\title{
Desempeño laboral de hombres y mujeres: opinan los empresarios*
}

\author{
Rosalba Todaro y Lorena Godoy ** \\ Laís Abramo****
}

\begin{abstract}
Resumo
La percepción de empresarios y ejecutivos sobre el desempeño laboral de hombres y mujeres tiene un efecto significativo en sus posibilidades de acceso al empleo y en sus condiciones de trabajo. Este artículo presenta los resultados de una investigación realizada en Chile, basada en una encuesta a 203 empresas y en 17 entrevistas a profundidad. Una de las principales conclusiones es que la opinión favorable o desfavorable de los empresarios respecto al desempeño de mujeres $y$ hombres obedece fundamentalmente a una definición previa de las características de las distintas ocupaciones, lo cual tiene poco que ver con los elementos técnicos u organizativos de las ocupaciones, y sí con el carácter masculino o femenino socialmente atribuido a ellas. Eso refleja la predominancia de un orden de género como criterio de caracterización y clasificación de las empresas y las ocupaciones como más o menos adecuadas para hombres o mujeres, definiendo con ello verdaderos territorios masculinos y femeninos en el mundo del trabajo.
\end{abstract}

Palavras-chave: Género, Trabajo, Imaginario Empresarial.

\footnotetext{
" Recebido para publicação em setembro de 2001.

** Centro de Estudios de la Mujer (CEM).

${ }^{* * * *}$ Oficina Internacional del Trabajo (OIT)
} 
Desempeño laboral de hombres y mujeres

\author{
Performance at Work of Men and Women: \\ Employers' Perceptions
}

\begin{abstract}
Employers' perceptions of men and women at work has a significant effect on the possibilities of them gaining access to employment, and on their work conditions. The article analyzes the results of a research based on a survey made of 203 companies in Chile and on 17 in depth interviews. One of the main conclusions is that what can best explain the negative or positive opinion of employers about women is an a priori definition of the characteristics of different occupations. Such "pre definition" has little to do with thecnical or organizational elements of the occupations, but rather to the masculine or feminine character socially attributed to them. We are therefore dealing with mechanisms constituting a gender order, which characterizes and classifies certain kinds of companies and occupations as more or less suitable for men or women, defining male and female territories in the world of work.
\end{abstract}

Key words: Gender, Work, Employers' Perception. 
Rosalba Todaro, Lorena Godoy, Laís Abramo

\section{Introducción}

La percepción de los empresarios en torno al desempeño laboral de mujeres y hombres, $y$, en especial, a las supuestas diferencias de productividad y costos a ellos asociados, son factores que inciden en gran medida en las posibilidades de acceso de trabajadores de uno y otro sexo al empleo, así como en sus condiciones de trabajo (remuneraciones y posibilidades de capacitación y promoción, entre otras). En esa medida, son elementos que pueden facilitar u obstaculizar la inserción laboral de diferentes grupos de trabajadores. En lo que se refiere a las mujeres, parte importante de estos obstáculos son derivados de una visión empresarial que es, bajo muchos aspectos, poco favorable a esa inserción.

El objetivo de este texto es discutir los resultados de una investigación realizada en 1998/1999, en la cual se pretendió analizar las percepciones de empresarios/as y ejecutivos/as chilenos/as respecto a estos temas. En artículo anterior ${ }^{1}$, en el cual presentábamos algunos de los supuestos e hipótesis de la investigación, señalábamos que era posible percibir, en el discurso empresarial, los impactos de procesos sociales tan relevantes como el fuerte aumento de la participación femenina en el mercado laboral, el incremento de su escolaridad (incluyendo la superior) y los cambios más generales ocurridos en las últimas décadas en las relaciones de género en la sociedad. En primer lugar, parece haber una mayor aceptación de la idea de que las mujeres pueden entrar al mundo del trabajo, sea porque ellas lo necesitan (para el sustento económico propio o del hogar), sea porque tienen derecho (por razones de autonomía personal, proyecto de vida, etc.). En suma, una mayor aceptación de la idea de que el mundo de la mujer no es sólo la familia o la esfera doméstica. En segundo

1 ABRAMO, Laís y TODARO, Rosalba. Género y trabajo en las decisiones empresariales. Revista Latinoamericana de Estudios del Trabajo, año 4, n ${ }^{\circ} 7$, 1998. 
Desempeño laboral de hombres y mujeres

lugar, especialmente en empresas más modernas y dinámicas, parece existir una mayor permeabilidad a la idea de la igualdad entre los géneros, lo que dificulta procedimientos explícitos de discriminación; en determinados ámbitos empieza a ser visto como "políticamente incorrecto" discriminar en términos de género, raza, etnia, discapacidades, etc. En tercer lugar, cada vez más se considera que la incorporación de mujeres a la empresa en tareas o funciones no tradicionales puede significar un aporte de nuevas capacidades (diferentes a las que son características de los hombres).

Sin embargo, persisten también, en el imaginario empresarial, nociones más tradicionales respecto al trabajo de las mujeres. La principal de ellas es la idea de que el compromiso de la mujer con su función materna y con el rol de principal (o única) responsable por el cuidado del universo doméstico interfiere negativamente en su desempeño laboral y aumenta los costos de su contratación. La permanencia y reproducción de esa imagen resiste a datos objetivos que indican, por ejemplo, una acentuada disminución de la tasa de fecundidad de las mujeres, en especial de las insertas en la fuerza de trabajo. Por otro lado, casi nunca se sustenta en estadísticas que pudieran indicar realmente que los costos laborales de las mujeres son superiores a los de los hombres, o cual es exactamente la influencia (negativa) de la maternidad o de las responsabilidades familiares en su desempeño laboral en general.

El objetivo central de la presente investigación era tratar de identificar las opiniones dominantes entre empresarios/as y ejecutivos/as chilenos/as respecto a estos temas. "Las mujeres son más o menos caras que los hombres?". "Las mujeres faltan más o menos al trabajo?". "Sus tasas de rotación voluntaria son superiores o inferiores?". "Ellas son más o menos disciplinadas y eficientes que ellos?". "La protección a la maternidad es adecuada o provoca problemas para la productividad?"

Nociones como estas emergían con frecuencia de una serie de estudios sobre el trabajo de las mujeres realizados tanto en 
Rosalba Todaro, Lorena Godoy, Laís Abramo

Chile como en otros países de América Latina, sin que se pudiera llegar a una conclusión más clara sobre cuales eran las opiniones dominantes entre los empresarios.

En el estudio que da origen a este artículo pretendíamos verificar cuales son esas opiniones y de qué factores dependen (sector productivo, tamaño de las empresas, porcentaje de mujeres en la fuerza de trabajo, ambiente cultural, etc). Pretendíamos también verificar si es posible identificar tendencias generales o opiniones claramente mayoritarias en la conformación del imaginario empresarial con relación a estos temas. Como la mayoría de las investigaciones hasta entonces realizadas consistían en estudios de caso basados en métodos cualitativos, optamos por centrar nuestro trabajo en la aplicación de una encuesta a una muestra representativa. ${ }^{2}$ Para complementar y profundizar la información, realizamos entrevistas en profundidad a una submuestra de 17 empresas localizadas en Santiago, las que permitieron analizar aspectos cualitativos difícilmente rescatables en una encuesta. Finalmente, se realizó un taller de discusión con un grupo de empresarios y empresarias de distintos sectores productivos, con quienes se discutieron algunos de los principales hallazgos de la investigación.

Las percepciones empresariales no son unívocas, ni las decisiones se toman en un contexto de información perfecta. En tanto grupo heterogéneo, portador de distintas experiencias, determinadas, entre otros factores, por sus distintas inserciones productivas, los empresarios y gerentes reaccionan de formas diferentes frente a las profundas transformaciones que vienen ocurriendo en el mundo del trabajo, en particular en lo que se refiere a los cambios en los patrones de inserción laboral de las

2 Como parte del Proyecto "Inserción laboral de las mujeres: el punto de vista empresarial" se aplicó una encuesta a 203 empresas de diversas regiones de Chile, de todos los sectores productivos y de distintos tamaños. La encuesta fue autoaplicada, modalidad que habitualmente introduce cambios en la estructura de la muestra. Por ello, se procedió a ponderar los resultados según la estructura por sector de actividad y tamaño del universo conocido de empresas del país. 
Desempeño laboral de hombres y mujeres

mujeres. $^{3}$ Esa diversidad se expresa al momento de tomar decisiones referidas a los recursos humanos, y condiciona significativamente la cantidad y calidad de las oportunidades laborales que se abren para hombres y mujeres.

Por otro lado, los procesos de decisión empresarial ocurren siempre en un contexto de información imperfecta y racionalidad limitada ${ }^{4}$, en el cual no inciden sólo los criterios técnicos y de racionalidad sustantiva, sino que también las culturas empresariales y laborales. Estas, a su vez, están fuertemente marcadas por criterios de género. Esto explica por qué, en los procesos de toma de decisión, siguen operando las rutinas, las resistencias al cambio, las inercias de los procedimientos establecidos y las imágenes de género dominantes.

Además, los procesos de decisión de los actores políticos y sociales están marcados por distintas lógicas (tales como, en el caso de los empresarios, la lógica de la búsqueda del beneficio, de la eficiencia, de la autoridad y del control), que son parte del proceso de conformación de esa "racionalidad limitada", y que, en cada caso concreto, pueden combinarse de maneras diferentes entre sí. Identificar la forma a través de la cual operan esas lógicas (así como la posible superposición, complementariedad o contradicción entre ellas) nos parecía importante para dilucidar los distintos mecanismos que pueden estar reproduciendo los obstáculos a la inserción laboral de las mujeres en igualdad de condiciones con los hombres.

\footnotetext{
3 Véase, entre otros, ARRIAGADA, Irma. Realidades y mitos del trabajo femenino urbano en América Latina. Serie Mujer y Desarrollo, n ${ }^{\circ} 21$, CEPAL, Julio de 1998; OIT. El acceso de las mujeres a puestos de dirección. Informe para el debate de la Reunión tripartita sobre el acceso de las mujeres a puestos de dirección, Ginebra, 1997.

4 Véase discusión a respecto en ABRAMO, Laís y TODARO, Rosalba, Género y trabajo en las decisiones empresariales. Op. cit.; SIMON, Herbert. De la racionalidad sustantiva a la procesal. En: HAHN, Frank e HoLLIS, Martin. (comps.), Filosofía y teoría económica, Fondo de Cultura Económica, México, 1986.
} 
Rosalba Todaro, Lorena Godoy, Laís Abramo

Las percepciones empresariales sobre el desempeño laboral de hombres y mujeres, y las imágenes que se configuran a partir de esas percepciones, muchas veces se construyen por comparación, cuando no por oposición. Eso significa que esas imágenes frecuentemente se estructuran en términos dicotómicos y jerarquizados; las mujeres son evaluadas por comparación con los hombres y a partir de criterios de "más" o "menos", "con" o "sin" determinadas calidades y atributos: más o menos caras, más o menos productivas, más o menos eficientes, más o menos comprometidas con el trabajo, con o sin capacidad de mando y decisión. Por detrás de esas comparaciones lo que está presente, en general, es la indagación sobre si vale o no la pena contratar mujeres, pagarles salarios equivalentes a los de los hombres, invertir en su capacitación, promoverlas, darles responsabilidades y oportunidades de mando.

La idea de que los costos laborales de las mujeres son más altos que los de los hombres, por ejemplo, tiene fuerte presencia en el imaginario empresarial, e incide significativamente en sus procesos de toma de decisión. ${ }^{5}$ Estos supuestos costos más elevados estarían relacionados básicamente a los mecanismos legales de protección a la maternidad, tales como los permisos pre y post natal, el horario especial para la lactancia, los permisos para el cuidado de hijos enfermos, la estabilidad para la mujer embarazada o en el período post parto, los servicios de cuidado infantil. Debido a eso, la percepción empresarial sobre los costos laborales de hombres y mujeres - y la relación de ese tema con la evaluación general que ellos hacen sobre el desempeño de trabajadores y trabajadoras - constituyó una preocupación central en la presente investigación. Nos interesaba llegar a alguna conclusión respecto a si realmente los empresarios consideraban

${ }^{5}$ Véase LERDA, Sandra y TODARO, Rosalba. ¿Cuánto cuestan las mujeres? Una análisis de los costos laborales de las mujeres. Sociología del Trabajo, $\mathrm{n}^{\circ} 30$ Madrid, Siglo XXI, 1997. Se entiende por costos laborales la suma de los costos monetarios y no monetarios en los que incurre el empleador por contratar y mantener en el empleo a un/a trabajador/a. 
Desempeño laboral de hombres y mujeres

que las mujeres eran "más caras" que los hombres, como evaluaban su productividad y comportamiento laboral, y de qué dependían esas percepciones: si variaban significativamente por sector productivo, tamaño de empresa, etc.

Las hipótesis de las cuales partimos en la investigación fueron básicamente cuatro. Primera: a pesar de que las resistencias de los empresarios y/o ejecutivos a contratar mujeres tienen como justificación importante el supuesto mayor costo relativo de la mano de obra femenina, su discurso se construye en torno a argumentos que van más allá de los que se podría definir como costos medibles en términos monetarios. Como se pudo verificar, tanto en la presente investigación, como en un estudio anterior $^{6}$, en general los empresarios no cuentan con ningún sistema de medición de costos laborales desagregados por sexo (que pudiera sustentar en términos más objetivos tales opiniones) y aún son una minoría los que tienen sistemas más elaborados de evaluación del desempeño y la productividad de sus trabajadores y trabajadoras. ${ }^{7}$ Segunda: las condiciones para la incorporación de mujeres a la fuerza de trabajo, así como las percepciones de los empresarios respecto de su desempeño laboral, varían según el tamaño de la empresa, siendo esperable encontrar mayores facilidades en las empresas grandes debido a la mayor flexibilidad para reorganizar los procesos de trabajo y absorber los eventuales problemas y costos derivados de la contratación de mano de obra femenina. Tercera: los empresarios que ya contratan mujeres, o que se encuentran en ramas más feminizadas de la actividad económica, tienden a adoptar opiniones más favorables con

6 ID., IB.

${ }^{7}$ El porcentaje de las empresas de la muestra que cuenta con cualquier tipo de evaluación de desempeño es inferior a los $10 \%(8,6 \%)$. Es aun más bajo el porcentaje que mide la productividad de sus trabajadores (6\%). En ningun caso la evaluación de desempeño o de productividad incopora el criterio del sexo del trabajador. Entre las 17 empresas entrevistadas, sólo una tenía un sistema de medición de la productividad (en función del cumplimiento de metas de producción según el cargo del empleado). 
relación al desempeño de la mano de obra femenina. Cuarta: los problemas de mayores costos laborales que pudiera presentar la mano de obra masculina debido a su condición de género (como por ejemplo, número más elevado de cargas familiares, posible mayor exposición a riesgos de accidentes laborales) tienden a no ser considerados por los empresarios.

Los resultados de la investigación indican, como se verá a continuación, que, a pesar de ser posible identificar algunas tendencias comunes en el discurso empresarial sobre las mujeres en el trabajo, este es, muchas veces, ambiguo y contradictorio. Hay muchos temas polémicos respecto a los cuales es difícil definir tendencias claras $e$ incluso opiniones significativamente mayoritarias. En algunos de los temas centrales ellas están claramente divididas.

Aun más difícil es establecer una relación clara entre esas opiniones y cualquiera de los factores definidos en nuestro sistema de hipótesis (tamaño de la empresa, sector productivo, porcentaje de mujeres). En cada una de esas categorías de clasificación, encontramos opiniones bastante diferentes. Llegamos a la conclusión de que, más que obedecer al sector o al tamaño de las empresas estudiadas, lo que más puede explicar la opinión negativa o positiva, favorable o desfavorable de los empresarios respecto a las mujeres es una definición previa de las características de las distintas ocupaciones, que tiene poco que ver con sus elementos técnicos u organizativos, y mucho más con el carácter masculino o femenino socialmente atribuido a esas ocupaciones. Estaríamos, por lo tanto, frente a mecanismos de constitución de un orden de género, que caracteriza y clasifica a cierto tipo de empresas (y más aún, a cierto tipo de ocupaciones al interior de cada empresa), como más o menos adecuadas para hombres o mujeres, definiendo verdaderos territorios masculinos y femeninos en el mundo del trabajo. Exactamente el mismo argumento, o la misma característica atribuida a una mujer trabajadora, aparece una vez como una virtud y otra vez como un defecto o una limitación, una vez como posibilidad y otra vez 
Desempeño laboral de hombres y mujeres

como imposibilidad de ejercer adecuadamente una función. Por ejemplo: para un empresario del sector gráfico, el principal impedimento para contratar mujeres en el área de producción no era la falta de calificación, la inexistencia de oferta adecuada o cualquier incapacidad técnica para el trabajo, sino su supuesta imposibilidad de trabajar en los turnos de la noche y el que ciertas ocupaciones hayan sido tradicionalmente desempeñadas por hombres. En las empresas de comunicaciones o del sector salud, sin embargo, las mujeres se concentran exactamente en ocupaciones caracterizadas, desde siempre, por el trabajo nocturno y en turnos (operadoras telefónicas y enfermeras). ¿Qué diferencia existiría, entonces, entre esas dos situaciones? Que el trabajo de enfermeras y operadoras telefónicas es considerado propio para mujeres y el del obrero de la industria gráfica es considerado impropio. Las explicaciones para eso no se encuentran en el terreno de las competencias técnicas, sino en razones de orden cultural e histórico, que siguen reproduciéndose a pesar de los profundos cambios ocurridos en los últimos años en las características técnicas de esas ocupaciones.

Otra conclusión del estudio es que, a pesar de todas las resistencias que persisten, las mujeres son, en promedio, mejor evaluadas que los hombres en su desempeño laboral. Lo que sí sigue siendo muy importante, y eso está relacionado al punto anterior, es la idea de que hay habilidades y ventajas que son propias de los hombres y otras, diferentes, que son propias de mujeres. Eso quizás no fuera un problema si esas diferencias no se convirtieran en desigualdades; o sea, si junto a ese señalamento de las diferencias (casi siempre identificadas por comparación o oposición) no se produjera una fuerte jerarquización de las supuestas virtudes y defectos atribuidos a hombres y mujeres, incidiendo significativamente en las posibilidades de unos y otras de acceder al empleo, a mejores remuneraciones y a cargos más valorados.

Finalmente, respecto a los costos laborales, la percepción predominante es que los costos indirectos de las mujeres son más 
altos. Sin embargo, los resultados de la investigación, además de evidenciar la existencia de un porcentaje importante de empresarios que no tiene esa opinión, muestran también que, en general, se está aludiendo a aquellas situaciones que, sin generar gastos monetarios adicionales al empleador, a su juicio afectan o podrían afectar la productividad de la empresa. Otra vez el argumento, que nunca está sustentado en mediciones sistemáticas, es ambiguo e impreciso, y parece estar referido mucho más a una lógica del orden y del control que a una lógica de los beneficios monetarios.

Vale señalar que la percepción de esas supuestas "perturbaciones del orden" al interior de la empresa (que se relacionan básicamente a la situación actual, futura o probable de las mujeres como madres y a su compromiso con las responsabilidades familiares), se estructuran con referencia a un paradigma de organización del trabajo y de la producción que sigue siendo concebido sin tomar en cuenta sea la creciente participación femenina en la fuerza de trabajo, sea una serie de necesidades y demandas que empiezan a ser expresadas también por los trabajadores del sexo masculino. A pesar de los cambios ocurridos en la participación de mujeres y hombres en el mercado de trabajo y en la familia, las empresas aun se estructuran a partir de la noción de que los trabajadores quieren y pueden hacer del trabajo su prioridad principal, por encima de la familia, la comunidad y otros aspectos relativos a su vida privada. En otras palabras, los modelos del desempeño deseable en el trabajo están pensados con relación a un paradigma de trabajador que no tiene familia que requiera de su tiempo, ni vida personal fuera del trabajo. Implícitamente se supone un trabajador que no se enferma, que no se accidenta, que no hace ninguna labor comunitaria, es decir, un individuo que vive el trabajo como esfera dominante y prácticamente exclusiva de su vida. 
Desempeño laboral de hombres y mujeres

\section{Percepciones sobre el desempeño en el trabajo}

Lo primero que quisimos evaluar es si existe entre los empleadores una idea generalizada que indique que hombres o mujeres, como conjunto, son considerados mejores o peores trabajadores. Aunque se supone que no hay corrientemente afirmaciones explícitas de tal tipo, sí es frecuente escuchar generalizaciones tales como: "Las mujeres ganan menos porque presentan más problemas como trabajadoras".

Para esta evaluación se solicitó a los/as encuestados/as calificar de 1 a 7 a trabajadoras y trabajadores en 16 características laborales ${ }^{8}$ consideradas beneficiosas para el buen funcionamiento de las empresas, que fueron seleccionadas a partir de la importancia atribuida a ellas por empleadores, según estudios realizados con anterioridad y la literatura empresarial. Además, se incluyó en la encuesta una serie de afirmaciones que introducían diferenciaciones entre hombres y mujeres (referidas a costos laborales, productividad, comportamiento en el trabajo, atributos y calidad de la oferta de trabajo), frente a las cuales se requería contestar el grado de acuerdo. Estas afirmaciones fueron elegidas por ser mencionadas frecuentemente por empresarios y ejecutivos $\mathrm{o}$, en algunos casos, porque persistentemente se afirma lo contrario.

\subsection{Las mujeres son mejor evaluadas}

El promedio general de notas que los encuestados asignaron a los trabajadores y trabajadoras fue de 5,5 puntos para las mujeres y 5,3 puntos para los hombres, mostrando, por lo tanto, una diferencia no significativa, pero ligeramente favorable a las

8 Puntualidad, Compromiso con el trabajo, Identificación con los objetivos de la empresa, Lealtad con la empresa, Facilidad para adaptarse a innovaciones, Rapidez en el aprendizaje, Interés en capacitarse, Capacidad para trabajar en equipo, Concentración en el trabajo, Productividad, Confiabilidad, Disciplina, Flexibilidad, Responsabilidad, Disposición para el trabajo y Baja conflictividad. 
mujeres. Esto implica que las mujeres como trabajadoras son evaluadas en un nivel similar a los hombres trabajadores, desestimando así algunas afirmaciones que suponen que las mujeres serían menos aptas para el trabajo remunerado fuera de la casa.

Si se analiza el promedio de notas para cada una de las características según el sexo del/a trabajador/a, se observa que las diferencias tampoco son significativas. Las notas promedio de los hombres fluctúan, según sea la característica considerada, entre un mínimo de 4,7 puntos y un máximo de 5,7, mientras que las de las mujeres fluctúan entre 5 y 5,8; por lo tanto, también aquí las calificaciones asignadas por los empleadores a las mujeres son ligeramente superiores.

Aunque las notas obtenidas por las mujeres son, para todas las características investigadas, más altas que las de los hombres, el máximo de las diferencias es de 3 décimas de punto: un porcentaje algo mayor de empresarios opina que las mujeres son más comprometidas con el trabajo, tienen más facilidad para adaptarse a las innovaciones y son más confiables, disciplinadas y responsables. 
Desempeño laboral de hombres y mujeres

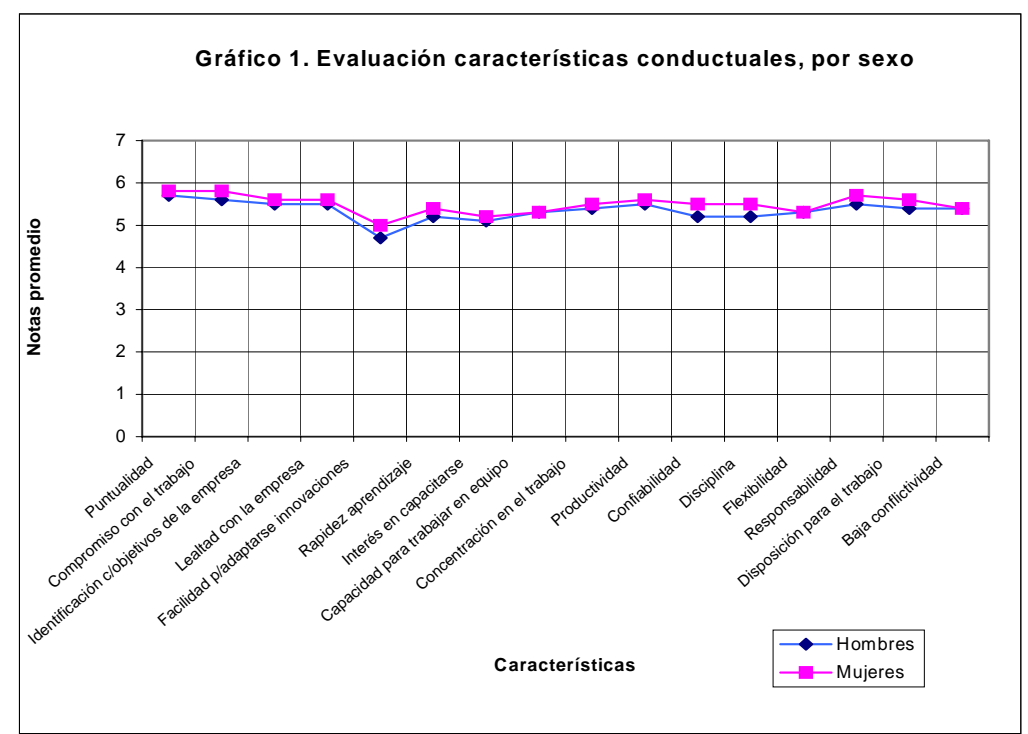

Esa valoración difiere por sector. Las notas promedio asignadas a las mujeres son superiores a las de los hombres en la mayoría de los sectores (de manera significativa en el caso de la Agricultura, con un promedio de 6,1 para las mujeres y 5,2 para los hombres), son iguales en uno de ellos (Comercio, donde se encuentran las peores evaluaciones para ambos: promedio 5,0), e inferiores sólo en el sector Transporte y Comunicaciones (6,2 y 6,6 puntos respectivamente), donde ambos son evaluados muy positivamente. También varían por sector las características mejor o peor evaluadas, lo que posiblemente se relaciona con las características de los puestos de trabajo y con los cargos que ocupan hombres y mujeres, en cada caso. Por ejemplo, las mujeres tienen significativamente mejor evaluación en los ítems facilidad para adaptarse a innovaciones y rapidez en el aprendizaje de nuevos procedimientos en los sectores Agrícola y Financiero, y peor en Transporte y Comunicaciones. El interés en 
capacitarse es peor evaluado en el sector Financiero y mejor en el Agrícola, en ambos con diferencias de casi dos puntos. A su vez, son consideradas más flexibles en el sector Financiero y notoriamente menos en Transporte y Comunicaciones.

En sólo uno de los sectores considerados (Transporte y Comunicaciones) los empresarios atribuyen a los hombres notas superiores a 6 . En cambio, para las mujeres estas notas se pueden hallar en casi todos los sectores (excepto Comercio), y las características que son con mayor frecuencia mejor evaluadas son compromiso con el trabajo y puntualidad. Es interesante destacar que el Sector Financiero, considerado como el más moderno y con frecuentes cambios en la tecnología, en la normativa y en la organización del trabajo, evalúa muy positivamente en las mujeres la facilidad para adaptarse a innovaciones y la rapidez en el aprendizaje.

Pero también es importante relacionar la evaluación más positiva hecha por los empresarios y ejecutivos sobre el trabajo de las mujeres al tipo de inserción y de oportunidades ocupacionales que se les otorga. Por ejemplo, en el sector Agrícola, el 89\% de las trabajadoras son clasificadas como operarias de baja especialización, siendo allí donde encontrarían oportunidades, lo cual parece contradictorio con la calidad a ellas atribuida de adaptarse a las innovaciones y de su interés en capacitarse. Por otro lado, consultados sobre la percepción de cambio en la composición por sexo de los trabajadores, sólo el $1 \%$ de los encuestados del sector Agrícola indica que están entrando o entrarán más mujeres. La percepción ampliamente mayoritaria entre los empresarios y ejecutivos de este sector de que la composición por sexo de los trabajadores no variará refleja la rigidez de la segregación ocupacional allí existente, valorándose las características laborales de las mujeres solamente en las actividades que se supone ellas pueden $y / 0$ deben ocupar.

Consecuentemente, podemos afirmar que las características conductuales en el trabajo se expresan y son apreciadas de manera diferente según el cargo, el tipo de empresa, el medio 
Desempeño laboral de hombres y mujeres

ambiente y las condiciones laborales, entre otros factores, los cuales no es posible analizar a partir de esta encuesta. El hecho de que ciertas características de los trabajadores se manifiesten o no y sean valoradas positiva o negativamente por las empresas dependerá, por lo tanto, en gran medida, de los cargos a que uno $\mathrm{u}$ otro sexo tengan acceso.

En las entrevistas en profundidad se pudo analizar algunas de estas diferencias y los problemas derivados de las características de ciertos puestos de trabajo, los que a veces se confunden con las atribuidas al sexo del trabajador que mayoritariamente los ocupa. Por ejemplo: la gerencia de una empresa de telecomunicaciones señala que las condiciones de trabajo en el cargo de telefonista son muy estresantes, lo que lleva a un ausentismo más alto en esa función que en el promedio de la empresa. El hecho de que todas las telefonistas sean mujeres eleva la tasa de ausentismo femenino, pero esto no deriva del hecho de que sean mujeres, sino fundamentalmente de las características del puesto de trabajo que ocupan. Más aun, los entrevistados consideran que las mujeres son elegidas para este cargo por tener mayor resistencia a estas condiciones de trabajo. Esto lleva al contrasentido de que ellas se hacen pasibles de una evaluación negativa por un atributo considerado positivo en ese trabajo. Por otra parte, las características que definen a un "buen trabajador" varían considerablemente según la ocupación desempeñada. Por ejemplo, no se valora de igual manera la puntualidad de un gerente que la de un vendedor. Por lo tanto, la evaluación de hombres y mujeres como trabajadores está mediada por los cargos que ejercen.

\subsection{Qué se dice y qué se está dispuesto a reconocer}

Uno de los resultados de esta investigación es la desmitificación respecto de la unanimidad de opinión que existiría entre los empleadores respecto de ciertas características de trabajadores y trabajadoras. Cuando se pide a los encuestados 
Rosalba Todaro, Lorena Godoy, Laís Abramo

que expresen su opinión (su grado de acuerdo o desacuerdo) respecto a afirmaciones usuales en el ambiente empresarial, si bien es cierto que se pueden identificar algunas tendencias, en la mayoría de los casos ellas no son absolutamente homogéneas o siquiera mayoritarias (Cuadro 1). Por otra parte, existe una alta proporción de encuestados que dicen que no están "ni de acuerdo ni en desacuerdo" con las afirmaciones que la encuesta propone. Sólo en un caso el porcentaje es de un dígito; el resto fluctúa entre un $20 \%$ y un $60 \%$. Este tipo de respuesta podría indicar la inexistencia de un criterio formado respecto de la afirmación, un rechazo a los términos en que ella fue planteada, o un deseo más activo de no pronunciarse que el simple "no sabe" o "no responde", lo que parece ocurrir especialmente en las respuestas respecto de afirmaciones valóricas, tales como la honestidad o la confiabilidad de los/as trabajadores/as.

\section{a. Costos laborales y productividad}

Es mayoritaria la percepción de que los costos indirectos de las mujeres son más altos (54\%). Sin embargo, es interesante llamar la atención sobre el hecho de que una idea que, en el discurso empresarial suele considerarse "de sentido común", a la hora de afirmarlo en una encuesta, aparece como la opinión de sólo la mitad de los encuestados. El porcentaje que expresa su desacuerdo con la afirmación, aunque mucho más bajo, es significativo (23\%).

Hay solamente un sector (Transporte y Comunicaciones) en que el porcentaje de encuestados que considera que los costos indirectos de las mujeres son más altos es insignificante $(2,8 \%)$. En todos los demás, el acuerdo supera al desacuerdo y, en casos tan diferentes como los de los sectores Agrícola y Financiero, hay coincidencia casi unánime con esta afirmación. A la vez, la mayoría (54\%) de las empresas medianas no está de acuerdo con la afirmación de que los costos indirectos de las mujeres son más 
Desempeño laboral de hombres y mujeres

altos, mientras en las pequeñas este porcentaje es bastante inferior (menos del 10\%).

La eficiencia y la productividad de hombres y mujeres en el trabajo es un tema frecuente en el debate sobre los costos laborales según el sexo de los trabajadores. La idea subyacente es que la maternidad es un problema para las empresas y muchas veces se dice que la protección a la maternidad es excesiva. Dado que los costos directos de la licencia maternidad son asumidos por el Estado a través del sistema de salud, el tema se plantea especialmente con relación a posibles problemas de productividad generados por los reemplazos con personas que necesitan adaptarse al cargo. Pero, al mismo tiempo, aparece en el debate la idea de que esa eventual disminución de la productividad se podría compensar por la mayor eficiencia de las mujeres.

La opinión "la licencia maternidad es un problema para la productividad" concita el acuerdo del $47 \%$ de los encuestados. Considerando que esta es una afirmación que se plantea frecuentemente como una verdad absoluta, es interesante verificar que el acuerdo no llegue al $50 \%$ y que el desacuerdo alcance casi al $30 \%$.

Es importante recordar aquí que la evaluación que realizaron las empresas sobre productividad, asignándole nota a trabajadores y trabajadoras, favorece a las mujeres, aunque solo sea de manera leve. Esto podría significar - a manera de hipótesis - que el problema de eventuales efectos negativos de la licencia maternal sobre la productividad es más que compensado por la mayor productividad de las trabajadoras y que, además, esto afecta a un porcentaje limitado de la población activa femenina, debido a la baja tasa de fecundidad y el corto período de la vida activa ocupado en la reproducción biológica. ${ }^{9}$

9 Al momento del último censo (1992) menos del $20 \%(18,6 \%)$ de las trabajadoras chilenas tenían algún hijo menor de 6 años y sólo el $9 \%$ entre 0 y 2 años. 
Rosalba Todaro, Lorena Godoy, Laís Abramo

Cuadro 1

Grado de acuerdo con afirmaciones (porcentajes ponderados)

\begin{tabular}{|l|c|l|l|l|}
\hline AFIRMACIONES & Acuerdo & $\begin{array}{l}\mathrm{Ni} \text { ac. } \\
\mathrm{Ni} \\
\text { des. }\end{array}$ & $\begin{array}{l}\text { Desacue } \\
\text { rdo }\end{array}$ & $\begin{array}{l}\mathrm{ns} / \\
\mathrm{nr}\end{array}$ \\
\hline COSTOS LABORALES Y PRODUCTIVIDAD & & & & \\
\hline Los costos indirectos de las mujeres son más altos & 54 & 20 & 23 & 3 \\
\hline $\begin{array}{l}\text { La licencia maternidad es un problema para la } \\
\text { productividad }\end{array}$ & 47 & 22 & 29 & 2 \\
\hline La protección a la maternidad es excesiva & 20 & 33 & 46 & 2 \\
\hline Las mujeres son más eficientes & 28 & 53 & 18 & 2 \\
\hline COMPORTAMIENTO EN EL TRABAJO & & & & \\
\hline Las mujeres tienen baja tasa de rotación externa & 43 & 23 & 28 & 6 \\
\hline Los hombres faltan menos que las mujeres & 54 & 7 & 38 & 1 \\
\hline Los hombres tienen mejor disposición para el trabajo & 28 & 35 & 35 & 1 \\
\hline Los hombres son más disciplinados & 24 & 31 & 44 & 1 \\
\hline $\begin{array}{l}\text { CALIDAD DE LA OFERTA DE TRABAJO Y } \\
\text { ATRIBUTOS "PERSONALES" }\end{array}$ & & & & \\
\hline Las mujeres no tienen la capacitación adecuada & 17 & 29 & 47 & 5 \\
\hline Los hombres son menos acuciosos & 43 & 34 & 19 & 5 \\
\hline Los hombres son más honestos & 14 & 60 & 26 & 1 \\
\hline Las mujeres son más confiables & 32 & 46 & 20 & 1 \\
\hline
\end{tabular}

En dos sectores (Financiero y Transporte y Comunicaciones) es insignificante el porcentaje de acuerdo. Eso significa que la gran mayoría de los encuestados no considera que la licencia maternidad sea un problema para la productividad. En los sectores de Servicios y Comercio, caracterizados por un alto porcentaje de mano de obra femenina y en el cual, por ese motivo, se puede esperar una mayor incidencia de licencias relacionadas a la maternidad, casi la mitad de los encuestados ( $40 \%$ en un caso y $46 \%$ en otro) tampoco considera que estas sean un problema para la productividad (mientras 31 y $43 \%$ expresan la opinión contraria). Por ultimo, tres sectores (Agrícola, Electricidad, Gas y agua, e Industria), el acuerdo es ampliamente 
Desempeño laboral de hombres y mujeres

mayoritario, o sea, un porcentaje de encuestados que varia de $75 \%$ a $98 \%$ considera que sí, la licencia maternal afecta negativamente la productividad de las empresas.

Cuadro 2

La licencia maternidad es un problema para la productividad por sector

(\% ponderados)

\begin{tabular}{|l|c|c|l|c|}
\hline & De acuerdo & $\begin{array}{l}\text { Ni acuerdo } \\
\text { Ni desacuerdo }\end{array}$ & $\begin{array}{l}\text { En } \\
\text { desacuerdo }\end{array}$ & $\mathrm{ns} / \mathrm{nr}$ \\
\hline Agrícola & 97,6 & 1,2 & 1,2 & 0 \\
\hline Comercial & 31,3 & 22,0 & 45,6 & 1,2 \\
\hline El.gas,agua & 75,0 & 6,3 & 15,6 & 3,1 \\
\hline Financiero & 5,7 & 0 & 94,3 & 0 \\
\hline Industrial & 81,8 & 13,2 & 5,0 & 0 \\
\hline Servicios & 42,6 & 11,5 & 40,2 & 5,7 \\
\hline Trans.Com. & 2,8 & 90,4 & 0,6 & 6,2 \\
\hline
\end{tabular}

El sector Agrícola no debería sufrir las consecuencias de los permisos maternales, ya que una gran proporción de las mujeres es contratada por temporada. En el caso de los sectores Electricidad, Gas y Agua, e Industrial, a pesar de que la gran mayoría de los encuestados considera que los permisos maternales afectan negativamente a la productividad, declaran preferir en la contratación a mujeres entre 25 y 40 años, rango de edades donde se concentra la reproducción. Ese mismo tramo de edad es el que prefiere en un $95 \%$ el sector Financiero, al mismo tiempo que los encuestados no coinciden con la idea de que la licencia maternal tendría un efecto negativo sobre la productividad. El sector Agrícola, a su vez, prefiere casi unánimemente contratar mujeres menores de 25 años.

También es relevante la diferenciación de opiniones que se produce según el porcentaje de mujeres en la empresa. En aquellas en las cuales la participación femenina es mayor (superior a los $40 \%$ ), es menor la proporción de encuestados que considera que la licencia maternal tiene un impacto negativo en la 
Rosalba Todaro, Lorena Godoy, Laís Abramo

productividad ( $19 \%$ en las empresas que tienen entre 40 y $59 \%$, y $33 \%$ en empresas con más del $60 \%$ de mujeres); a su vez, en las empresas con menos de $40 \%$ de mujeres, aumenta la proporción de encuestados que expresa esa opinión. Si estas licencias afectan la productividad, a primera vista se podría suponer que el problema sería más acentuado donde hay mayor proporción de mujeres. ¿Significa esto una inconsistencia del discurso empresarial, donde hay más mitos que resultados de una evaluación objetiva de los efectos de las licencias maternales sobre el desempeño laboral de las mujeres y la productividad de las empresas? Otra hipótesis es que las empresas que contratan una alta proporción de mujeres encuentran que su productividad "específica" compensa los inconvenientes y/o que éstas, por preferir la mano de obra femenina, elaboran estrategias para enfrentar los problemas que se pudieran ocasionar como consecuencia de la maternidad.

Otro hallazgo interesante de la investigación es que, al mismo tiempo que para el conjunto de las empresas encuestadas un considerable porcentaje manifiesta como problema las licencias maternales, sólo el $20 \%$ está de acuerdo con que la protección a la maternidad es excesiva, y casi el $50 \%$ manifiesta desacuerdo con esa afirmación. Esto revela que, aun considerando que las licencias maternales afectan la productividad, esto no es visto por la mayoría de los encuestados como razón para reducir la protección a la maternidad, la que, además, abarca otros derechos de las trabajadoras madres. En un taller realizado con empresarios y ejecutivos en el contexto de esta investigación, junto con abogar por mantener la protección a la maternidad, se proponían formas más flexibles de uso de las licencias pre y post natal. Dependiendo del puesto de trabajo, también se consideraba la posibilidad de colaborar desde la casa - aprovechando las ventajas de las tecnologías de comunicación - con las personas que tienen que reemplazar a la trabajadora con licencia.

La mayoría de los encuestados no tiene opinión formada acerca de si las mujeres son más eficientes que los hombres (53\%). 
Desempeño laboral de hombres y mujeres

Sin embargo, el porcentaje que considera que sí, las mujeres son más eficientes (28\%) es superior al que está en desacuerdo con esa idea (18\%). La diferencia por sector es importante, aunque, salvo en el caso del sector Agrícola, el porcentaje que no se pronuncia es notable. Este sector, casi en su totalidad $(97 \%)$ considera que las mujeres son más eficientes que los hombres. Eso probablemente está relacionado al hecho que el trabajo femenino es considerado allí irremplazable, opinión fundamentada en su supuesta "natural" habilidad manual y prolijidad.

\section{b. Comportamiento de hombres y mujeres en el trabajo}

Se indagó sobre cuatro afirmaciones relacionadas con el comportamiento en el trabajo de mujeres y hombres: Las mujeres tienen baja tasa de rotación externa, Los hombres faltan menos que las mujeres, Los hombres tienen mejor disposición para el trabajo y Los hombres son más disciplinados.

La afirmación los hombres faltan menos que las mujeres es el único caso en que la respuesta "ni de acuerdo ni en desacuerdo" es menor del $10 \%$, lo cual muestra que hay posiciones definidas al respecto, ya sea para manifestarse de acuerdo como en desacuerdo. Y aunque la mayoría de los encuestados (54\%) considera que sí, los hombres faltan menos al trabajo que las mujeres, el $38 \%$ de ellos no comparte esa opinión. Al mismo tiempo hay sectores en que no se observan diferencias de magnitud entre el acuerdo y el desacuerdo, lo que debe alertar contra una de las ideas más corrientes sobre el desempeño laboral de las mujeres, casi nunca sustentada con estadísticas. Según un estudio realizado en España ${ }^{10}$ con una encuesta de 2 mil casos, las tasas de ausentismo se explican por diferencias en las condiciones de trabajo, mientras que el sexo no tiene fuerza explicativa: las diferencias por sexo resgistradas son mínimas, aunque el ausentismo masculino sea levemente superior al femenino.

${ }^{10}$ CASTILLO, Juan José. El absentismo laboral de la mujer: el fin de un mito. En: CASTILlo, J. J. El trabajo del sociólogo. España,Editorial Complutense, 1994. 
En cuanto a otra de las ideas que se escucha con frecuencia entre los empleadores, o sea, que las tasas de rotación femenina son superiores a las masculinas, la mayoría de los encuestados opina que eso no es así. El 43\% afirma que las mujeres tienen una baja tasa de rotación externa y el $28 \%$ está en desacuerdo, mientras que hay un $23 \%$ que no se pronuncia. Además, en las entrevistas a empleadores se menciona, en algunos sectores, que la estabilidad de las mujeres en la empresa compensa otros problemas, tales como el de las ausencias relacionadas con el cuidado de los hijos.

La afirmación los hombres tienen mejor disposición para el trabajo concita solamente un $28 \%$ de acuerdo, cuestionando también una idea muy marcada. El resto se reparte de manera pareja entre los que están en desacuerdo (35\%) y los que no están ni de acuerdo ni en desacuerdo (35\%).

El desacuerdo respecto a la supuesta mejor disposición de los hombres para el trabajo es notorio en el sector Agrícola (97\%) y en el sector Financiero (87\%) y casi duplica el promedio en el sector Servicios (61\%), siendo estos los sectores que presentarían las opiniones más favorables a las mujeres en este aspecto. En Transporte y Comunicaciones el desacuerdo es también mayor que el promedio (46\%), pero el acuerdo se expresa en un porcentaje equivalente. El sector Comercio es el que tendría una percepción más desfavorable de las mujeres en este sentido: muestra el menor nivel de desacuerdo (5\%), un acuerdo que alcanza el $46 \%$, con un $49 \%$ que no se pronuncia.

Sólo el $24 \%$ de los encuestados considera que los hombres son más disciplinados. En este caso, el desacuerdo es mayoritario (44\%), aunque la respuesta ni acuerdo ni desacuerdo es significativamente alta (31\%). El único sector que tiene un grado de acuerdo significativo y un desacuerdo muy bajo con esta afirmación es el Comercial. Nuevamente los grandes desacuerdos lo presentan los sectores Agrícola (97\%) y el Financiero $(88 \%)$ a los que se suma Transporte y Comunicaciones (92\%) y Servicios (63\%), pero también son altos en Electricidad, Gas y Agua y el 
Desempeño laboral de hombres y mujeres

sector Industrial, lo que sería consistente con la idea generalizada de que la disciplina es una virtud femenina.

\section{c. Calidad de la oferta de trabajo y atributos personales}

La afirmación de que las mujeres no tienen la capacitación adecuada sólo obtiene un acuerdo del $17 \%$ y un desacuerdo mayoritario, cosa que sucede en todos los sectores, salvo en el Industrial, donde el desacuerdo es apenas inferior al acuerdo. Las empresas grandes y medianas manifiestan un desacuerdo muy superior a las pequeñas y lo mismo sucede con las empresas que tienen una mayor proporción de mujeres. Estas respuestas cuestionan la idea de que el problema para la inserción laboral femenina es su falta de capacitación. ${ }^{11}$ Sin embargo, esto no excluye el problema del acceso restrictivo a la capacitación para las tareas que no son consideradas apropiadas para mujeres en las imágenes vigentes de lo femenino y lo masculino.

$\mathrm{El}$ acuerdo sobre que los hombres son menos acuciosos es muy superior al desacuerdo ( $43 \%$ y $19 \%$, respectivamente). Esto es consistente con la imagen de género dominante, según la cual las mujeres y no los hombres son las apropiadas para el trabajo meticuloso, prolijo y que requiere paciencia y dedicación.

$\mathrm{El}$ alto porcentaje que responde estar ni de acuerdo ni en desacuerdo (34\%) está sustentado por un $85 \%$ en el sector Financiero -un sector donde la segregación sexual de las ocupaciones es menor. A su vez, el alto acuerdo refleja el $94 \%$ en el sector Agrícola y $59 \%$ en el sector Industrial, sectores caracterizados por una mayor segregación. El sector Servicios

\footnotetext{
${ }^{11}$ Esa conclusión se refuerza al analizar las respuestas a otra pregunta de la encuesta, referente a las razones por las cuales los empresarios y ejecutivos consideraban que existían cargos considerados inconvenientes para las mujeres: en la gran mayoría de los casos esas razones aludían a la falta de fuerza o capacidad física, en menor grado al tema de los riesgos en el trabajo; solamente el $1 \%$ se refería a la falta de capacitación y/o especialización técnica de las mujeres.
} 
Rosalba Todaro, Lorena Godoy, Laís Abramo

también manifiesta un alto porcentaje de acuerdo (45\%), pero también es alto el porcentaje de indefinición.

En los casos de afirmaciones que aparecen ligadas a valores, tales como la confiabilidad de las mujeres o la honestidad de los hombres, la proporción de las respuestas que no indican ni acuerdo ni desacuerdo es mayoritaria $(46 \%$ y $60 \%$ respectivamente). Esto parece indicar la negativa a pronunciarse en temas tan delicados, aunque estas opiniones con frecuencia se manifiestan espontáneamente en entrevistas poco estructuradas, donde siempre queda la posibilidad, se use o no, de relativizar la respuesta.

Las diferencias entre estas preguntas por sector son notorias. En ningún caso es mayoritario el acuerdo con la afirmación los hombres son más honestos y en cuatro casos el porcentaje de acuerdo es cero, mientras que en varios es mayoritario el desacuerdo (como, por ejemplo, el sector Financiero, en el cual el porcentaje de desacuerdo alcanza a 86\%). Este desacuerdo no significa que necesariamente opinen que los hombres son más deshonestos, aun cuando algunos entrevistados afirman que los "problemas con dinero" difícilmente se presentan con mujeres.

Hemos visto que las opiniones de los encuestados sobre los distintos temas generalmente difieren por sector, tamaño $y$ porcentaje de mujeres en la empresa. Sin embargo, es difícil establecer alguna regularidad. En primer lugar, ninguna de las variables independientes tomada aisladamente permite explicar de manera concluyente las diferencias en las respuestas, una vez que el tamaño de la encuesta no es suficiente para cruzar las distintas variables y detectar categorías más finas de empresas combinando las variables mencionadas. Por otra parte, el análisis de los resultados de la encuesta, complementados por las entrevistas realizadas a una submuestra de empresas nos permite revisar y afinar las hipótesis. Creemos que es principalmente en ocupaciones específicas y en los espacios laborales en que se desarrollan, donde se construye el carácter femenino o masculino del trabajo, lo que genera verdaderos territorios masculinos y 
Desempeño laboral de hombres y mujeres

femeninos, que inciden en las posibilidades de acceso de mujeres y hombres al trabajo y en la valoración que se hace de los mismos.

Las opiniones de los empresarios y ejecutivos sobre hombres y mujeres en el trabajo dependerán, por lo tanto, del lugar que ocupen, de las características de los puestos de trabajo y de las construcciones sociales que indican lo que hombres y mujeres deben o pueden hacer. Al mismo tiempo, la organización del proceso de trabajo no depende solamente de factores técnicos, sino también de estas formas de concebir la organización social y de la producción en términos de género. De este modo, puede o no permitir compatibilizar el quehacer laboral con la vida privada de trabajadoras y trabajadores, y con las necesidades de la reproducción social. Las posibilidades de mejorar la relación entre las distintas necesidades sociales y personales dependerán de factores que no siempre evolucionan a la misma velocidad y en el mismo sentido.

\section{Perfiles laborales de hombres y mujeres: ¿virtudes femeninas y defectos masculinos?}

Cuando se habla con los empresarios y ejecutivos en entrevistas no estructuradas, sin preguntas cerradas que establecen parámetros más rígidos a las respuestas, como sucede en las encuestas, ellos se explayan sobre una serie de virtudes y defectos de los hombres y mujeres en el trabajo. Llama la atención el hecho que los ejecutivos asocien a las mujeres trabajadoras un número mucho mayor de virtudes que a sus colegas del sexo masculino. Y viceversa, que asocien a los hombres un número mayor de defectos. Sin embargo, es preciso analizar con detención las virtudes y defectos atribuidos a cada uno de ellos, en función de las posibilidades que ellas podrían abrir a unos y otras en el trabajo.

En relación con las características que atribuyen a las trabajadoras mujeres, los empresarios destacan como virtudes el 
orden, la prolijidad y delicadeza, la disciplina, la tolerancia a trabajos rutinarios, la eficiencia, concentración y responsabilidad, adaptabilidad y capacidad de establecer relaciones humanas, honradez, compromiso y lealtad. Y señalan como defectos la debilidad física, el "abuso", en ciertas situaciones, de una imagen de debilidad, la conflictividad, competitividad y cierta violencia solapada entre mujeres.

Por su parte, entre las virtudes atribuidas por los empresarios y ejecutivos a los hombres destacan la capacidad física, la "fortaleza de carácter" para enfrentar situaciones problemáticas y la rigurosidad y agilidad para cambiar. Entre los defectos, se menciona el desorden, la falta de prolijidad y tosquedad, impulsividad y baja tolerancia a trabajos rutinarios o que requieran permanecer en el mismo lugar varias horas, menor capacidad de concentración y de "pensar en varias cosas a la vez", menor responsabilidad y compromiso con los objetivos de la empresa, además de una cierta rigidez que dificulta la adaptabilidad a diversas situaciones, así como la agresividad que tiende a surgir en grupos de trabajadores hombres.

Como se puede apreciar, muchas de las virtudes y defectos se definen por contraste, o clara oposición, entre hombres y mujeres: ellas son prolijas y ordenadas, ellos toscos $y$ desordenados; ellas tienen mayor tolerancia a trabajos rutinarios, ellos son más impulsivos y con menor capacidad de concentración; ellos tienen mayor fuerza física y ellas son más débiles.

Lo que interesa es conocer cómo los empresarios valoran estas 'diferencias' entre trabajadores y trabajadoras, e identificar que tipo de funciones y ocupaciones estarían habilitando a hombres y mujeres. Para ello, junto con analizar la composición por sexo de la estructura ocupacional a través de la información que entregaba la encuesta, en las entrevistas se ahondó en las características que los empresarios asignaban a los trabajos desempeñados por hombres y mujeres. 
Desempeño laboral de hombres y mujeres

Se puede apreciar que, en general, las virtudes masculinas se asocian a cargos que suponen manejo de poder, toma de decisiones, otorgan mayor status, por un lado, o requieren mayor fuerza física y cierta agresividad, por otro; por su parte, las virtudes femeninas vinculan a las mujeres, en gran medida, con ocupaciones con poco poder de decisión, menor calificación, de carácter más rutinario, estresantes, de gran minuciosidad y relacionados con el trato a personas (Cuadro 3).

\section{Cuadro 3}

Características de las Ocupaciones de Hombres y Mujeres en las empresas entrevistadas

Todos los sectores

\begin{tabular}{|l|l|}
\hline Ocupaciones de Hombres & Ocupaciones de Mujeres \\
\hline - toma de decisión & - poca toma de decisión \\
- manejo de poder & - poco manejo de poder \\
- innovación e improvisación & - repetitivos, estresantes \\
- más calificados (habilidades & - poco calificados (habilidades \\
aprendidas) & y destrezas naturales) \\
- requieren fuerza física, & - livianos, "fáciles" \\
agresividad, dominio de & (producción) \\
conocimientos técnicos (por & - escaso dominio de \\
ejemplo, manejo máquinas en & conocimientos técnicos \\
producción) & (excepción de costureras) \\
- mayor status & - poco status \\
\hline
\end{tabular}

Parece evidente el papel que juega la diferencia de sexos en la calificación laboral que hacen los empleadores de trabajadoras y trabajadores, ya que los empleos, como lo sostiene Maruani ${ }^{12}$, no se definen de manera independiente de quien los realiza. La diferencia de sexos está presente en el discurso empresarial como un criterio para jerarquizar y valorizar los trabajos. Ello explica el

${ }^{12}$ MARUANI, Margaret. La calificación, una construcción social sexuada. Economía y Sociología del Trabajo, Madrid, 1993. 
Rosalba Todaro, Lorena Godoy, Laís Abramo

que muchas de las habilidades y aptitudes atribuidas a las mujeres, que seguramente son muy importantes para garantizar la calidad de los productos y servicios, la eficiencia y la productividad de las empresas, no se caractericen como calificaciones profesionales, sino como atributos personales naturales, sean físicos o psicológicos. Explica también que la forma en que algunos entrevistados nombran a las trabajadoras, independiente de sus calificaciones y situaciones ocupacionales, expresen, por una parte, una asociación con imágenes del ámbito doméstico (al nombrarlas como "madres" o "esposas"), y por otra, con mucho más frecuencia, con lo que Reygadas denomina el status no-adulto de las trabajadoras (al nombrarlas como "niñas", independiente de su edad). ${ }^{13}$

Estos discursos sobre hombres y mujeres en el trabajo, y las imágenes de género a ellos subyacentes, inciden en las decisiones empresariales relativas a la contratación, promoción y capacitación de trabajadores de uno y otro sexo. El carácter masculino o femenino atribuido a ciertas ocupaciones es un elemento central de esas imágenes y del proceso de configuración de verdaderos territorios masculinos y femeninos en el trabajo.

\subsection{Territorios de hombres y territorios de mujeres}

La configuración de estos territorios masculinos y femeninos, que marcan el campo en el cual se definen las características de las ocupaciones o funciones consideradas más apropiadas para hombres o mujeres, es una de las formas a través de las cuales se expresa la percepción de los empresarios de las

\footnotetext{
${ }^{13}$ Se habla, por ejemplo, de "las niñas que venden bonos [para atención médica]", de trabajos atractivos para "una niña que tenga hijos y que mantenga el hogar", de la "niña que pedía más permiso para cuidar a su guagua (bebé)", o de las "niñas muy ligeras de genio". REYGADAS, Luis. Fábricas con aroma de mujer. Las nuevas culturas del trabajo vistas desde la óptica de género. En ABramo, L. y ABREU, A.R.P. (eds.) Gênero e Trabalho na Sociologia Latinoamericana. São Paulo, ALAST/SERT, 1998.
} 
Desempeño laboral de hombres y mujeres

identidades de género asociadas a trabajadores y trabajadoras. Lo que interesa analizar aquí es: a) la forma como los empresarios caracterizan las distintas categorías ocupacionales a partir de estas imágenes de género y, a partir de ahí, las definen como más o menos apropiadas para mujeres $\mathrm{u}$ hombres; b) como esas definiciones inciden tanto en la evaluación del desempeño de hombres y mujeres en el trabajo como en la reproducción de la segregación por sexo que sigue caracterizando la estructura ocupacional de las empresas.

\section{a. El acceso de mujeres a cargos de dirección: "el gerente puro, por así decirlo, son más hombres" 14}

Varios estudios han señalado la presencia de significativas barreras para el acceso de mujeres a los puestos gerenciales, es decir "obstáculos artificiales $e$ invisibles basados en prejuicios psicológicos y estructurales" 15 que limitan el ingreso a cargos de alto nivel y definen ciertos patrones de inserción. Así, se indica que las pocas mujeres que acceden a ese tipo de cargos suelen concentrarse en áreas como recursos humanos, comunicación, administración, consideradas menos estratégicas para la empresa en comparación con las de desarrollo de productos o gestión financiera; y que sus oportunidades, en general, se concentran en los niveles inferior e intermedio de la dirección, y en los sectores de servicios, financiero y la administración pública.

Los resultados de la investigación apuntan en el mismo sentido. En la mayoría de las empresas entrevistadas se destaca el fuerte predominio de hombres en las gerencias y jefaturas de más alto nivel ("el gerente puro"). Las mujeres que acceden a puestos de dirección se concentran en subgerencias y jefaturas de niveles menores, especialmente en áreas de recursos humanos y personal.

\footnotetext{
${ }^{14}$ Expresión utilizada por el ejecutivo de una Institución de Salud Previsional (Isapre) entrevistado.

${ }^{15}$ OIT. El acceso de las mujeres a puestos de dirección... Op. cit.
} 
Rosalba Todaro, Lorena Godoy, Laís Abramo

A pesar del fuerte predominio masculino en estas áreas, sólo un $5.7 \%$ de los empresarios encuestados consideró que las gerencias y jefaturas eran cargos inconvenientes para ser ocupados por mujeres. Los entrevistados señalaron que la escasez de mujeres en la alta gerencia se debía a su falta de motivación para ocupar esos cargos, ya que ellas no tendrían tanto interés por el status a ellos asociado y prefieren "guiar" o "coordinar" en lugar de "mandar". Sin embargo, encontramos evidencias de la persistencia de fuertes obstáculos al acceso de mujeres a puestos de mando, como, por ejemplo, el rechazo y hostilidad de los trabajadores a aceptar jefaturas femeninas en empresas industriales masculinizadas. Eso indica que la falta de motivación atribuida a las mujeres para ocupar estos cargos no puede ser entendida sin considerar que ello responde también a la existencia de serias barreras de acceso.

Hay cierto consenso entre los entrevistados en atribuir a las mujeres que acceden a cargos de dirección un estilo de dirección más democrático y horizontal. Por otro lado, algunas entrevistadas (gerentes de recursos humanos de empresas financieras, de servicios, transporte y comunicaciones), mencionaron que las mujeres solían ser más eficientes durante la jornada de trabajo, ya que sus obligaciones familiares no les permiten continuar con el trabajo en la casa; eran también más responsables, adaptables, comprensivas y organizadas y con una mayor capacidad para establecer relaciones humanas, pensar en varias cosas a la vez y abordar las situaciones desde distintos puntos de vista. A juicio de estas ejecutivas, gran parte de las características mencionadas son habilidades desarrolladas por las mujeres en el ejercicio de roles familiares ${ }^{16}$, que, en el ámbito laboral, pasan a ser virtudes. Algunos autores han denominado estas habilidades como "destrezas suaves", que convertirían a las mujeres en especialistas

\footnotetext{
${ }^{16}$ La ejecutiva de una empresa de comunicaciones afirma que las mujeres tienden a hacer del trabajo una extensión del hogar en cuanto a la necesidad de establecer relaciones más cálidas y centradas en las personas.
} 
Desempeño laboral de hombres y mujeres

emocionales de las relaciones ${ }^{17}$ y que podrían propiciar cambios en la cultura empresarial, tales como el trabajo en equipo o formas más horizontales de ejercicio del poder. ${ }^{18}$

Esta situación contrasta con la vivida en empresas del sector industrial con un alto porcentaje de hombres, donde, si bien se han dado procesos de incorporación de mujeres en cargos de dirección (que, por lo tanto, no son espacios impermeables), es donde encontramos las mayores resistencias. En la empresa Gráfica (96\% de mano de obra masculina), como parte de un proceso de profesionalización de los puestos de dirección, se nombró a una mujer como subgerenta de planificación y control de la área de producción. Jefes y trabajadores reaccionaron con mucha hostilidad ante la presencia de una mujer en un "terreno de hombres", lo que se tradujo en acciones hostiles, como rayarle el auto, llamarla a la casa para molestarla e incluso inventar y difundir por la empresa que tenía una relación amorosa con un trabajador. Según el entrevistado, los costos personales de esta situación para la subgerenta han sido muy altos y el rechazo de sus subordinados se expresa en un cuestionamiento de sus atributos personales "femeninos" y no de su calificación técnica; por el contrario, se destaca su idoneidad profesional para el cargo. El problema radica, fundamentalmente, en que se trata de una mujer en un terreno de hombres por excelencia (el área de producción de una empresa masculinizada), donde una condición necesaria para ejercer la jefatura sería la "fortaleza de carácter", entendida como un atributo masculino que se manifiesta en la capacidad de enfrentar emocionalmente situaciones problemáticas, en ese caso, la hostilidad abierta de los subordinados, motivada justamente por lo que se considera la "intromisión" de una mujer en un territorio masculino.

\footnotetext{
${ }^{17}$ Newman, 1995 y Osborne, 1993 apud REYGADAS, Luis. Fábricas con aroma de mujer... Op. cit.

${ }^{18}$ HolA, Eugenia y TODARO, Rosalba. Los mecanismos del poder. Hombres y mujeres en la empresa moderna. Centro de Estudios de la Mujer - GEL, Argentina, 1992.
} 
Rosalba Todaro, Lorena Godoy, Laís Abramo

\section{b. La presencia femenina en la producción y en las áreas operacionales}

A pesar del porcentaje significativo de mujeres en áreas de producción en las empresas del sector industrial estudiadas ${ }^{19}$, la visión de los ejecutivos es que, en estas áreas, se concentran los cargos más inconvenientes para mujeres ${ }^{20}$, ya que se trata de trabajos que requieren más esfuerzo físico y "sacrificio", se realizan muchas veces en turnos de noche, en ambientes poco gratos (sucios) y que revisten algún grado de peligrosidad. En cambio, la mayor fuerza física de los hombres, asociada a la "fortaleza de carácter" antes mencionada, los haría más aptos para asumir estas funciones riesgosas y "sacrificadas", como el manejo de maquinaria, la carga de material o la manipulación de material delicado, funciones esas que, a su vez, están asociadas a mayor responsabilidad, mayores remuneraciones y status.

Las labores que realizan las mujeres en la producción la mayor parte de las veces son caracterizadas como las más sencillas y livianas, las que no requieren gran fuerza física sino prolijidad, cuidado de detalles, paciencia y tolerancia a tareas repetitivas y que exigen permanecer mucho tiempo en el mismo lugar. Se trataría de trabajos de carácter secundario que, más que una calificación específica, requieren supuestos atributos femeninos, que se conciben más como destrezas naturales que como habilidades adquiridas, talento y no calificación, propia de la naturaleza femenina y de su relación con el ámbito doméstico. ${ }^{21}$

\footnotetext{
${ }^{19}$ Según los datos de la encuesta, $73 \%$ de las ocupadas en las empresas industriales fueron clasificadas como obreras.

${ }^{20}$ Un $51 \%$ de los encuestados señala que los trabajos más calificados de la producción o vinculados a ella, y un $47 \%$ de los trabajos manuales menos calificados de la producción, son inconvenientes para las mujeres.

${ }^{21}$ En la empresa de cerámica, se dice que la habilidad manual de las mujeres para pulir piezas tiene que ver con "el manejo de la mamadera, el pelar cebollas o cocinar"; también se señala, en empresas de otros sectores, que el trabajo de mujeres en áreas operacionales, como el de las operadoras telefónicas, requiere un "perfil más psicológico que técnico". Ese tipo de consideración, incluso de las
} 
Desempeño laboral de hombres y mujeres

Esta forma de caracterizar el trabajo de las mujeres tiene directa relación con el hecho de que las fábricas siguen siendo, en el imaginario de los empresarios y de los propios trabajadores, el territorio masculino por excelencia, en el que se exalta la fuerza física, los trabajos pesados y sacrificados. Y esto, claro está, no significa la exclusión absoluta de mujeres del trabajo industrial ${ }^{22}$, sino que define una inserción segregada a ciertas ramas y ocupaciones, muchas veces en condiciones precarias, que se expresa, entre otras cosas, en su confinamiento a puestos de trabajo caracterizados por la utilización de habilidades supuestamente relacionadas con la esfera doméstica. ${ }^{23}$ Para ilustrar este aspecto, es interesante mencionar el caso de las encuadernadoras en la empresa Gráfica, cuyo trabajo no es, a juicio del entrevistado "de alta especialización, pero sí de mucho cuidado", lo que requiere "dedicación y prolijidad". Por eso, la empresa exije exclusivamente mujeres, subcontratadas de manera temporal. Sin embargo, el ejectivo menciona que, al trabajar en los mismos recintos que los hombres, se produjeron problemas como acoso sexual, infidelidades ("líos de falda"), lo que llevó a la empresa a habilitar un lugar fuera del recinto principal para las encuadernadoras "casi en zonas aisladas (...) donde no va nadie,

própias mujeres al referirse a su trabajo, ha sido encontrado en varias investigaciones. Véase, entre otras, RISEK, Cibele y LEITE, Márcia. Dimensões e representações do trabalho feminino fabril. En ABRAMO, L. y ABREU, A.R.P. (eds.) Gênero e Trabalho na Sociologia Latinoamericana. São Paulo, ALAST/SERT, 1999; JENSON, Jane. The talents of women, the skills of men: flexible specialization and women. En WooD, Stephen. (ed.) The transformation of work? Unwin Hyman Ltd, Londres, 1989.

${ }^{22}$ En efecto, las cifras globales para Chile indican que el porcentaje de trabajadoras industriales sobre el total de las mujeres ocupadas $(13,5 \%)$ no es muy inferior al porcentaje de trabajadores industriales sobre el total de hombres empleados (17,5\%, datos del INE para 1997); la participación de la mano de obra femenina sobre el volumen total del empleo del sector es de $27 \%$ y ha crecido $47 \%$ entre 1985 y 1997.

${ }^{23}$ ABRAmo, L. y TODARO, R. Género y trabajo en las decisiones empresariales. Op. cit. 
Rosalba Todaro, Lorena Godoy, Laís Abramo

allá va un sólo hombre que está encargado de entregar y recibir los materiales". La caracterización del trabajo de las encuadernadernadoras como no calificado, junto con su aislamiento, parecen ser expresión de una cultura fabril que no mezcla los géneros y que, como lo han señalado otros autores, pretende a toda costa no ser "afeminada". ${ }^{24}$

\section{c. Profesionales y técnicos}

En las empresas estudiadas existe buena disposición para incorporar mujeres en los niveles profesionales, incluso en empresas con alto porcentaje de mano de obra masculina. Es el caso de la empresa Minera, que ha integrado a mujeres profesionales en cargos ejercidos hasta ese momento sólo por hombres: una ingeniera civil como supervisora de tronadura y una química como administradora de una planta productiva. ${ }^{25}$ Las áreas técnicas, si bien en muchos casos tienen un carácter masculino, agrupan ocupaciones muy diversas que varían mucho por sector. Por eso es necesario hacer distinciones. En algunas empresas del sector servicios, por ejemplo, se aprecia cierta apertura al ingreso de mujeres. La ejecutiva de la empresa de Informática señala que la primera mujer que entró al servicio técnico, hace 17 años, enfrentó muchas dificultades porque se trataba de "un mundo de hombres". Sin embargo, "eso ha ido cambiando con el tiempo, ella hizo su carrera, hoy es gerente del servicio técnico y hay más mujeres ahí". En la misma empresa Minera se han incorporado mujeres analistas químicas al trabajo

\footnotetext{
${ }^{24}$ Hoggart, 1990 apud REYGADAS, LUIS. Fábricas con aroma de mujer... Op. cit.

${ }^{25}$ En términos agregados, la presencia femenina en el grupo de profesionales y técnicos viene aumentando significativamente en América Latina, fenómeno que está asociado al aumento de sus tasas de participación y de sus niveles de escolaridad. Esa presencia ya alcanza a más del $50 \%$ en las zonas urbanas de muchos países, entre los cuales se destacan Chile, Costa Rica, México y Venezuela. VALDÉs y GOMÁRIZ. Mujeres latinoamericanas en cifras, volumen comparativo. Santiago, Instituto de la Mujer de España/FLACSO, 1995.
} 
Desempeño laboral de hombres y mujeres

en laboratorio. Sin embargo, en empresas del sector transporte y comunicaciones, la instalación y reparación de líneas telefónicas o vías ferroviarias es un trabajo desempeñado exclusivamente por hombres.

\section{d. Áreas administrativas}

Como se podría esperar, la mano de obra femenina predomina en las áreas administrativas, desempeñando una serie de cargos considerados "típicos" de mujeres: secretarias, contadoras, vendedoras y supervisoras, personal del área de recursos humanos, $\mathrm{y}$, en algunos casos, de bodega para inventariar mercadería. En las funciones menos calificadas de esa área, como auxiliares de aseo, encontramos a hombres y mujeres, $y$ en las funciones de cierre y apertura de oficinas, trámites bancarios y seguridad predominan los hombres.

En estos casos, el discurso empresarial destaca como habilidades propias de las trabajadoras la "capacidad de organización y orden" y la "mayor estabilidad y responsabilidad". Entre sus cualidades humanas se menciona una mayor honradez, compromiso, lealtad, fidelidad y buena presencia, todo lo cual hace a las mujeres mucho más aptas que los hombres para trabajos administrativos de confianza $\mathrm{y}$, especialmente, de atención al público. El entrevistado de la empresa que comerciaba productos electrónicos las describió como "más finas, con más tacto, la buena presencia da un aire especial, mejora el ambiente de trabajo, lo hace más alegre". Nuevamente, al igual que en las áreas productivas, las referencias tienen más que ver con un perfil psicológico y actitudinal que con características profesionales o técnicas. 
Rosalba Todaro, Lorena Godoy, Laís Abramo

\subsection{Las principales limitaciones de las mujeres en el trabajo}

Junto con los defectos o virtudes atribuidas por los empresarios y ejecutivos a hombres y mujeres, otro elemento que ayuda a entender la ubicación de cada uno en la estructura ocupacional y la configuración de territorios masculinos y territorios femeninos en la empresa, es la supuesta limitación de las mujeres para desempeñar ciertas ocupaciones. Además de la fuerza física y el riesgo, que aparecieron como las razones más importantes para justificar que determinadas ocupaciones sean consideradas inconvenientes para mujeres, se menciona su supuesta falta de disponibilidad para trabajar en turnos nocturnos y viajar. Nos parece necesario analizar estas supuestas limitaciones, especialmente las dos últimas, en relación con la realidad de algunos puestos ocupados exclusivamente por mujeres en las empresas estudiadas. Nos referimos a las operadoras telefónicas y las enfermeras, quienes durante todo el año cumplen con turnos de noche, y a las azafatas de transporte terrestre, cuyo trabajo consiste precisamente en viajar. La concentración de mujeres en esas ocupaciones, por un lado, confirma muchas de las tradicionales imágenes de género, ya que se trata de ocupaciones relacionadas a la atención al público y cuyos requisitos se refieren a un perfil "más psicológico que técnico"; por otro, claramente cuestiona las supuestas limitaciones que los ejecutivos atribuyen a las mujeres. ${ }^{26}$

${ }^{26}$ Cuando se consultó a la ejecutiva de una clínica por la supuesta dificultad de las enfermeras para hacer turnos nocturnos, esta señaló que esto no representaba ningún problema, porque "ellas mismas (...), al ponerse a estudiar esta profesión, saben que tienen que trabajar en turnos". Aunque reconoce que esto puede generar problemas en la vida familiar (afirma que en el área de salud, la mayoría de hombres y mujeres son separados o casados más de una vez), las enfermeras "se las arreglan (...) se las han arreglado toda su vida". La entrevistada destaca también que estas trabajadoras se caracterizan por bajos niveles de ausentismo y un alto nivel de responsabilidad. En el caso de las azafatas el entrevistado señala que todas son mujeres jóvenes "por razones de marketing, de buena presencia" y condiciones para atender público. 
Desempeño laboral de hombres y mujeres

Esta inconsistencia entre el discurso empresarial y algunas prácticas gerenciales, indica que la atribución de supuestas limitaciones a las mujeres para desempeñar determinadas funciones es bastante relativa y casuística: aparece cuando se trata de ocupaciones y territorios masculinos y desaparecen en los casos contrarios, o sea, en las ocupaciones desempeñadas casi exclusivamente por mujeres y asociadas a atributos femeninos. Es a partir de este discurso empresarial, expresión de identidades de género rígidas y bastante tradicionales en el mundo del trabajo, que se toman muchas de las decisiones que tienden a mantener dinámicas de segregación en el trabajo.

\section{Consideraciones finales}

El estudio evidencia la presencia de continuidades y cambios en el discurso empresarial sobre hombres y mujeres en el trabajo: por un lado, la emergencia de nuevas ideas y, por otro, la persistencia de imágenes tradicionales que, al mismo tiempo, se originan en y reproducen la segregación ocupacional por sexo existente al interior de las empresas y en el mercado de trabajo.

La investigación permite también desmistificar ciertas imágenes, entre ellas la de la inadecuación de las mujeres para un desempeño laboral eficiente y adecuado a las exigencias de las empresas en un mundo cada vez más competitivo: en general, cuando se pregunta explícitamente, y se demanda una respuesta sintética, definida y cuantificada de empresarios y ejecutivos, no aparecen grandes diferencias en la evaluación que hacen del desempeño laboral de hombres y mujeres. Más que eso: la pequeña diferencia que aparece en ese contexto es favorable a las mujeres.

El tamaño de la muestra no permite testar hipótesis más finas, dirigidas a verificar de manera más sistemática la relación 
entre las opiniones expresadas por los encuestados con factores tales como el tamaño de las empresas, el sector productivo, el porcentaje de mujeres en la fuerza de trabajo. Además, las opiniones parecen relacionarse fundamentalmente con la experiencia directa de cada uno de los informantes a partir de su realidad inmediata, o sea, de lo que sucede al interior de las empresas. En líneas generales se podría decir que las opiniones que se expresan a través de la encuesta son levemente más "progresistas" si comparadas a las que surgen de las entrevistas. La encuesta pone a los encuestados frente a afirmaciones generales que les exigen una tomada de posición más definida frente a determinados temas polémicos. En ese sentido, se podría relacionar las opiniones que ahí aparecen con las que se expresan en un ámbito más "público". El gran porcentaje que afirma no estar ni de acuerdo ni en desacuerdo con afirmaciones que, según estudios anteriores, son consideradas casi de sentido común en el discurso empresarial, indicaría que, en muchos casos, se están cuestionando los términos mismos en que se formula la pregunta. En las entrevistas, sin embargo, reaparecen esas mismas opiniones y formulaciones. En estas es más amplio el espacio para la argumentación $\mathrm{y}$, por lo tanto, para la expresión de la ambigüedad y de las contradicciones que parecen estar presentes en el discurso empresarial con relación a los temas propuestos. Las opiniones ahí expresadas parecen acercarse más a aquellas que aparecen en el espacio más privado, en el cual pierde eficacia la presión del "políticamente correcto".

Los cambios ocurridos en el mercado de trabajo se reflejan, aunque de manera ambigua $e$ incompleta, en el discurso empresarial: ellos reconocen que las mujeres tienen derecho al trabajo remunerado; en algunos casos se incentiva su contratación, ya que se les reconocen ciertas características asociadas positivamente a los nuevos estilos de gestión. El discurso empresarial de alguna manera dá cuenta de los cambios ocurridos en el mundo del trabajo y de los efectos que éstos han tenido en otros ámbitos de la vida social. Algunas de las opiniones 
Desempeño laboral de hombres y mujeres

"políticamente correctas" que se desprenden de la encuesta indican la ampliación de la legitimidad de las ideas relativas a los derechos de las mujeres.

Pero persisten y se reproducen las resistencias y las imágenes tradicionales sobre hombres y mujeres. Se siguen valorando de manera distinta (y desigual) los atributos laborales, lo que se refleja en distintas ( $y$ desiguales) oportunidades de acceso al empleo, remuneración, promoción y capacitación. Para las mujeres, el peso de los atributos personales identificados con lo femenino supera, con mucha fecuencia, un análisis más objetivo de sus calificaciones técnicas y sus características profesionales.

Persisten una serie de atributos negativos asociados a las mujeres, o evaluaciones (por veces tajantes) sobre sus imposibilidades y limitaciones (tales como trabajar en turnos nocturnos, viajar, trabajar horas extraordinarias, mayor ausentismo) que, además de no comprobados por información sistemática o registros estadísticos de cualquier tipo, se relacionan, más que con cualquier característica propia de las mujeres en el trabajo, con determinadas formas de organización empresarial que están en la base del surgimiento de ese tipo de problemas. En ese sentido es importante señalar que otras formas de organización de la producción y del trabajo, así como otros estilos de gestión empresarial, que permitieran, por ejemplo, jornadas de trabajo menos intensas y extensas, trabajos menos repetitivos y rutinarios, la creación de un ambiente laboral más "amigable", o una mejor conciliación entre la vida laboral y la vida domestica, podrían contribuir a la eliminación de una serie de problemas de desempeño, eficiencia y productividad laboral actualmente existentes, tanto en el caso de las mujeres como en el de los hombres. 